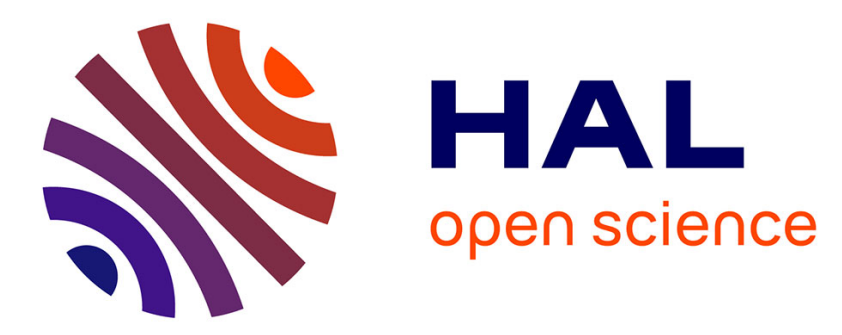

\title{
Oxidative cleavage of cycloalkenes using hydrogen peroxide and a tungsten-based catalyst: towards a complete mechanistic investigation
}

Tony Cousin, Gregory Chatel, Bruno Andrioletti, Micheline Draye

\section{- To cite this version:}

Tony Cousin, Gregory Chatel, Bruno Andrioletti, Micheline Draye. Oxidative cleavage of cycloalkenes using hydrogen peroxide and a tungsten-based catalyst: towards a complete mechanistic investigation. New Journal of Chemistry, 2021, 10.1039/D0NJ03592K . hal-03084823

\section{HAL Id: hal-03084823 \\ https://hal.science/hal-03084823}

Submitted on 2 Apr 2021

HAL is a multi-disciplinary open access archive for the deposit and dissemination of scientific research documents, whether they are published or not. The documents may come from teaching and research institutions in France or abroad, or from public or private research centers.
L'archive ouverte pluridisciplinaire HAL, est destinée au dépôt et à la diffusion de documents scientifiques de niveau recherche, publiés ou non, émanant des établissements d'enseignement et de recherche français ou étrangers, des laboratoires publics ou privés. 


\title{
New Journal of Chemistry
}

\section{ARTICLE}

Received 00th January 20xx, Accepted 00th January 20xx DOI: $10.1039 / x 0 x \times 00000 x$

\section{Oxidative cleavage of cycloalkenes using hydrogen peroxide and a tungsten-based catalyst: towards a complete mechanistic investigation}

\author{
Tony Cousin,${ }^{a, b}$ Gregory Chatel, ${ }^{a}$ Bruno Andrioletti ${ }^{b^{*}}$ and Micheline Draye ${ }^{a *}$ \\ The identification of the intermediates and by-products produced during the oxidative cleavage of cycloalkenes in the \\ presence of $\mathrm{H}_{2} \mathrm{O}_{2}$ and a tungsten-based catalyst for the production of dicarboxylic acids has been carried out under various \\ experimental conditions. On the basis of this mechanistic investigation and previous studies from the literature, a \\ complete reaction scheme for the formation of reaction products and by-products is proposed. In this hypothesis of \\ mechanism, the production of a hydroperoxyalcohol intermediate accounts for the two pathways proposed by Noyori and \\ Venturello for the formation of the targeted dicarboxylic acid. In addition, a Baeyer-Villiger oxidation of the mono- \\ aldehyde intermediate allows explaining the formation of short chain diacids observed as by-products during the reaction. \\ Hence, the proposed mechanism constitutes a real tool for scientists looking for a better comprehension and heading to \\ set up environmentally-friendly conditions for the oxidative cleavage of cycloalkenes.
}

\section{Introduction}

The oxidative cleavage of $\mathrm{C}=\mathrm{C}$ bonds has witnessed a growing interest for several decades as a key transformation to access value-added mono- and dicarboxylic acids from olefins. ${ }^{1-5}$ More specifically, dicarboxylic acids are major intermediates for the manufacture of important polyesters and polyamides materials but also for the production of daily products found in a wide range of applications such as lubricants, fibers, cosmetics, pesticides, pharmaceuticals and plasticizers. ${ }^{6,7}$ In the chemical industry, this class of compounds is mainly obtained by oxidative cleavage of unsaturated carboxylic acids and cycloalkenes. ${ }^{6,7}$ One of the oldest oxidative cleavage process was patented by DuPont in the 50s for the production of adipic acid. Since, this dicarboxylic acid is still manufactured via the aerobic oxidation of cyclohexane to cyclohexanol and cyclohexanone followed by the oxidative cleavage of either one or a mixture of both (ketone + alcohol $=$ KA Oil) with nitric acid. ${ }^{8}$ This industrial process leads to the formation of adipic acid in $95 \%$ yield with an annual production of 4 million tons. ${ }^{7,9}$ Adipic acid production is mainly dedicated to the synthesis of nylon 6,6 but also to plasticizers, lubricants and polyurethane resins. ${ }^{7,10}$

Despite the major importance of adipic acid for key

${ }^{a}$ LCME, Univ. Savoie Mont Blanc, 73000 Chambéry, France.

E-mail: micheline.draye@univ-smb.fr

${ }^{b}$ Univ Lyon, Université Claude Bernard Lyon 1, INSA-Lyon, CPE-Lyon,

ICBMS UMR CNRS 5246, Campus Lyon-Tech la Doua, Bât. Lederer

43 Boulevard du 11 Novembre 1918, 69622 Villeurbanne, France.

E-mail: bruno.andrioletti@univ-lyon1.fr

† Electronic Supplementary Information (ESI) available.

See DOI: 10.1039/x0xx00000x applications, the DuPont process results in the production of large volumetric amounts of nitrous oxide. Actually, up to 400,000 metric tons of $\mathrm{N}_{2} \mathrm{O}$ arise from the oxidative cleavage of KA Oil by nitric acid, representing $8 \%$ of the total anthropogenic production of this greenhouse gas. ${ }^{11,12}$ Nitrous oxide is particularly harmful towards the environment as it causes ozone depletion, smog, acid rains and its global potential warming is 300 times higher than $\mathrm{CO}_{2} \cdot{ }^{13-16}$ Even if efforts to reduce the amount of released $\mathrm{N}_{2} \mathrm{O}$ through recycling, thermal and catalytic decomposition ${ }^{10,14,16,17}$ have been done, the energy consumption for adipic acid production remains high because this multi-step reaction is performed at temperatures reaching up to $160{ }^{\circ} \mathrm{C} .{ }^{7,8,13}$

These observations have prompted researchers to develop more environmentally-friendly routes for the production of dicarboxylic acids through cycloolefin oxidative cleavage. In this context, hydrogen peroxide has been considered to replace commonly used oxidants. Indeed, $\mathrm{H}_{2} \mathrm{O}_{2}$ presents many advantages for the development of greener oxidation reactions: it is a widely available oxidant with $47 \%$ of active oxygen content, non-toxic, only releases water as theoretical by-product and does not require temperatures above $100{ }^{\circ} \mathrm{C}$ to perform oxidations. ${ }^{18,19}$ The $\mathrm{H}_{2} \mathrm{O}_{2}$-mediated oxidative cleavage of cycloalkenes has been widely documented in the literature. The last trends in the development of sustainable catalytic systems for this reaction have been recently reviewed. ${ }^{5}$ In particular, the use of hydrogen peroxide in association with tungsten-based catalysts has shown to be a promising combination to decrease the environmental impact of the cycloalkene oxidative cleavage. Indeed, compared to other transition metals used for this reaction, tungsten-based catalysts are low cost, ${ }^{20,21}$ non-toxic ${ }^{22,23}$ and react with $\mathrm{H}_{2} \mathrm{O}_{2}$ to 
produce peroxotungstate compounds highly active toward olefins. $^{24,25}$

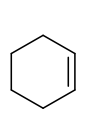

1

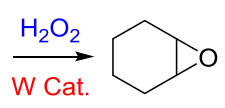

2

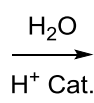$$
\text { Hat. }
$$

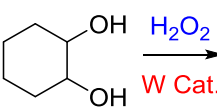

3

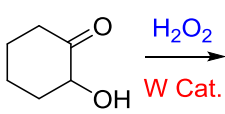

4

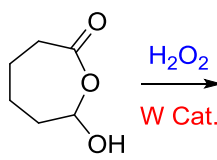

5

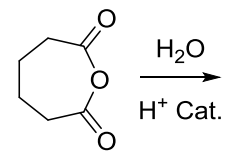

6<smiles>O=C(O)CCCCC(=O)O</smiles>

7

Scheme 1: Oxidative cleavage of cycloalkenes with $\mathrm{H}_{2} \mathrm{O}_{2}$ and a tungsten-based catalyst according to Noyori. ${ }^{11,26}$

Among the numerous studies dealing with $\mathrm{H}_{2} \mathrm{O}_{2}$-mediated cycloalkene oxidative cleavage with tungsten-based catalysts, a large majority of publications exposes the reaction mechanism suggested by Noyori et al. ${ }^{11,26}$ for rationalizing the formation of dicarboxylic acids from cycloalkenes (Scheme 1).

This mechanism involves six reaction steps including an alkene epoxidation, an epoxide hydrolysis, a first alcohol oxidation, a Baeyer-Villiger oxidation, a second alcohol oxidation and a cyclic anhydride hydrolysis (Scheme 1). Even if intermediates $\mathbf{2}$ to $\mathbf{4}$ have been unambiguously identified and described in the literature, the production of intermediates $\mathbf{5}$ and 6 through Baeyer-Villiger enlargement have not been highlighted yet. Their presence in the oxidation mechanism has been so far justified through indirect studies and computational modelling. ${ }^{27-29}$

No complete mechanism has been established to date to explain the formation of the targeted dicarboxylic acid from the hydroxy-ketone intermediate 4. Moreover, among studies on the oxidative cleavage of cycloolefins, several by-products are often observed along with the expected dicarboxylic acid. Indeed, from 1 to $5 \%$ of additional dicarboxylic acids, shortened by 1 to 3 carbon atoms compared to the targeted one, are observed at the end of the reaction. ${ }^{11,30,31}$ Despite their occurrence in studies, no hypothesis for their formation has been suggested so far.

The accurate comprehension of the reaction pathways for product and by-products formation is of prime interest to determine the conditions favouring the production of the targeted dicarboxylic acid and minimizing the formation of these by-products.

In this study, we aim at confirming and completing the mechanisms proposed in the literature for the oxidative cleavage of cycloalkenes with $\mathrm{H}_{2} \mathrm{O}_{2}$ and a tungsten-based catalyst through the structural determination of intermediates and by-products of the reaction. Studies of the reaction at different stages and under different experimental conditions allow highlighting the structure and amount of by-products formed during the reaction.

\section{Experimental}

All chemicals were used without further purification and purchased from Acros, Aldrich, Alfa Aesar, Honeywell and Fluka.
Gas chromatography was performed on a HP 6890 Series gas chromatograph from Hewlett Packard using a flameionization detector and equipped with an Optima-5MS Accent capillary column (dimethylpolysiloxane, $30 \mathrm{~m} \times 0.25 \mathrm{~mm} \times 0.25$ $\mu \mathrm{m})$ from Marcherey Nagel. All analyses were undertaken with helium as carrier gas $\left(24 \mathrm{~mL} \cdot \mathrm{min}^{-1}\right)$ in split mode (split ratio: $1: 40$ ) and an injector and a detector both heated at $290{ }^{\circ} \mathrm{C}$.

Mass spectra were recorded on an Agilent $5973 \mathrm{~N}$ Mass Selective Detector coupled to an Agilent 6890 GC and equipped with an Optima 5 capillary column (dimethylpolysiloxane $30 \mathrm{~m} \times 0.32 \mathrm{~mm} \times 0.25 \mu \mathrm{m}$ ) from Macherey-Nagel.

\section{Cyclohexene oxidative cleavage}

The reactions were performed following the procedure described in the reference study. ${ }^{11,26}$ Hydrogen peroxide (35 wt.\%, 2.6-525 g, 4.4 eq.) was added to a mixture of tungstenbased catalyst (1 mol\%) and Phase Transfer Catalyst (PTC: Aliquat $336^{\circledR}$ or $\mathrm{Oct}_{3} \mathrm{MeN}^{+} \mathrm{HSO}_{4}^{-}, 1$ mol\%) into a round bottom flask. The solution was vigorously stirred with a magnetic stirring bar at room temperature for $10 \mathrm{~min}$ to solubilize as much of catalyst as possible. After addition of cyclohexene (0.5-100 g, 1 eq.), the round bottom flask was equipped with a condenser and successively heated to $75^{\circ} \mathrm{C}$ for $30 \mathrm{~min}, 80^{\circ} \mathrm{C}$ for $30 \mathrm{~min}, 85^{\circ} \mathrm{C}$ for $30 \mathrm{~min}$, and $90{ }^{\circ} \mathrm{C}$ for $6 \mathrm{~h} 30 \mathrm{~min}$ while stirring at 1,000 rpm. After $8 \mathrm{~h}$, the reaction medium was cooled to room temperature before being placed at $5{ }^{\circ} \mathrm{C}$ overnight. Then, the resulting white precipitate was separated from the aqueous solution by filtration, washed 3 times with cold deionized water and dried under reduced pressure. Sodium sulphite was added portion-wise to the aqueous filtrate until complete decomposition of remaining hydrogen peroxide. After acidification with sulfuric acid to $\mathrm{pH}=1$, water was then evaporated under reduced pressure and $20 \mathrm{~mL}$ acetone was added to the solid residue. After separation of the organic solution from inorganic salts by filtration, acetone was eliminated under reduced pressure. Solid residues from the aqueous filtrate and precipitated adipic acid were analyzed by gas chromatography for quantification of all reaction products by internal standard method (dodecane used as internal standard) after derivatization with N-Obis(trimethylsilyl)trifluoroacetamide for $2 \mathrm{~h}$ at $50{ }^{\circ} \mathrm{C}$. Reaction by-products were identified by GC/MS (characterization is available in $\mathrm{ESI}+$ ). 


\section{Cycloalkene epoxidation}

The cyclopentene, cyclohexene and cyclooctene epoxidations were performed as follows. Into a $250 \mathrm{~mL}$ round bottom flask an aqueous solution of hydrogen peroxide $(280 \mathrm{mmol}, 26.90 \mathrm{~g}$, 1.5 eq., 35 wt.\%) was added to a mixture of $\mathrm{H}_{2} \mathrm{WO}_{4}(1.4 \mathrm{mmol}$ $0.346 \mathrm{~g}, 0.75 \mathrm{~mol} \%)$ and Aliquat $336^{\circledR}(1.4 \mathrm{mmol}, 0.56 \mathrm{~g}, 0.75$ mol\%). The aqueous solution was stirred at room temperature with a stirring bar for $10 \mathrm{~min}$ before adding the cycloalkene (185 mmol). The round bottom flask was equipped with a condenser before stirring the biphasic mixture at $80^{\circ} \mathrm{C}$ without any incubation period at $1,000 \mathrm{rpm}$ for $30 \mathrm{~min}$.

At the end of the reaction, the aqueous phase was separated from the organic layer, thoroughly extracted by $\mathrm{CH}_{2} \mathrm{Cl}_{2}$ or diethyl ether $(3 \times 30 \mathrm{~mL})$ in order to recover remaining cycloalkene and newly formed products, and concentrated under reduced pressure. Isolation and analysis of nonextracted epoxidation by-products contained into the aqueous phase were undertaken according to the same procedure as previously. Reaction by-products were identified by GC/MS (characterization is available in ESI+).

\section{Results and discussion}

Within the scope of our study, we decided to limit our investigations to cyclohexene, cyclopentene and cyclooctene for the epoxidation and to cyclohexene for the oxidative cleavage. Indeed, the oxidative cleavage of cycloolefins is welldescribed in the literature on these small-sized cycloalkenes and affords the dicarboxylic acids with over $75 \%$ yields. ${ }^{5}$ Besides, the reaction performed on larger rings such as cyclooctene and cyclododecene results in low yields, generally below $30 \%$ because of transannular reactions occurring on the epoxide derivatives of these medium-sized cycloalkenes. ${ }^{5,32}$ Among the studies on the oxidative cleavage of cyclic alkenes with $\mathrm{H}_{2} \mathrm{O}_{2}$ and a tungsten-based catalyst, those from Noyor and co-workers are still a reference in terms of green chemistry. Indeed, the reaction conditions involve 4.4 equivalents of $30 \% \quad \mathrm{H}_{2} \mathrm{O}_{2}, \quad 1$ mol\% of $\mathrm{Na}_{2} \mathrm{WO}_{4}$ and $\mathrm{Oct}_{3} \mathrm{MeN}^{+} \mathrm{HSO}_{4}^{-}$as a Phase Transfer Catalyst (PTC). These conditions allow to perform the oxidative cleavage of $100 \mathrm{~g}$ of cyclohexene from 75 to $90{ }^{\circ} \mathrm{C}$ in $8 \mathrm{~h}$ and without any organic solvent. Adipic acid is isolated in 93\% yield. ${ }^{11,26}$

During our studies, the oxidative cleavage of cyclohexene was investigated under the conditions described by Noyori and co-workers. The production of adipic acid as well as the byproducts was followed by gas chromatography (GC). At first, the reaction was studied under the conditions used for the oxidative cleavage of $100 \mathrm{~g}$ of cyclohexene, corresponding to $600 \mathrm{~mL}$ of reaction volume, ${ }^{11,26}$ and on 8 and $3 \mathrm{~mL}$ scales in order to decrease the amounts of reactants used per run. The obtained results are gathered in the Table 1.

At $600 \mathrm{~mL}$ reaction scale, the oxidative cleavage of cyclohexene leads to $83 \%$ adipic acid yield (Table 1, Entry 2) instead of the $93 \%$ published in the literature (Table 1, Entry $1)$. These results can be ascribed to the formation of 1,2 cyclohexanediol, 2-cyclohexanone and glutaric acid observed in 0.5 to $4.5 \%$ yields. Moreover, the reaction performed under Noyori's conditions revealed the formation of by-products that were not described in the original work. Thus, little amounts (< $0.5 \%$ ) of 5-hydroxypentanoic, 5-oxopentanoïc and succinic acid were detected during our study. When the reaction volume was decreased from $600 \mathrm{~mL}$ to $8 \mathrm{~mL}$ and $3 \mathrm{~mL}$, the yield of adipic acid decreased from $83 \%$ to $47 \%$ and $39 \%$ respectively (Table 1, Entries 2, 3 and 4). However, the same by-products were produced in similar yields than with $600 \mathrm{~mL}$ reaction volume, leading to an unsatisfactory mass balance. Hence, the oxidative cleavage yields and selectivities lower than 50\% observed with reaction volumes below $10 \mathrm{~mL}$ can be explained by a cyclohexene loss by volatilization during the $8 \mathrm{~h}$ of reaction. Indeed, despite the experimental care, some of the solution has been volatilized. This would explain the choice of $100 \mathrm{~g}$ of starting cycloalkene chosen in the reference study, ${ }^{11,26}$ that ensure a minimum impact of volatilization of the reactant on the yield of the reaction. A reaction volume of $8 \mathrm{~mL}$ was chosen for the rest of the study, guaranteeing a reasonable yield and the use of a minimum amount of reactants (Table 1 , Entry 3).

Table 1 Oxidative cleavage of cyclohexene in the presence of $\mathrm{H}_{2} \mathrm{O}_{2}, \mathrm{Na}_{2} \mathrm{WO}_{4}$ and $\mathrm{Oct}_{3} \mathrm{MeN}^{+} \mathrm{HSO}_{4}{ }_{4}$ at different reaction volumes

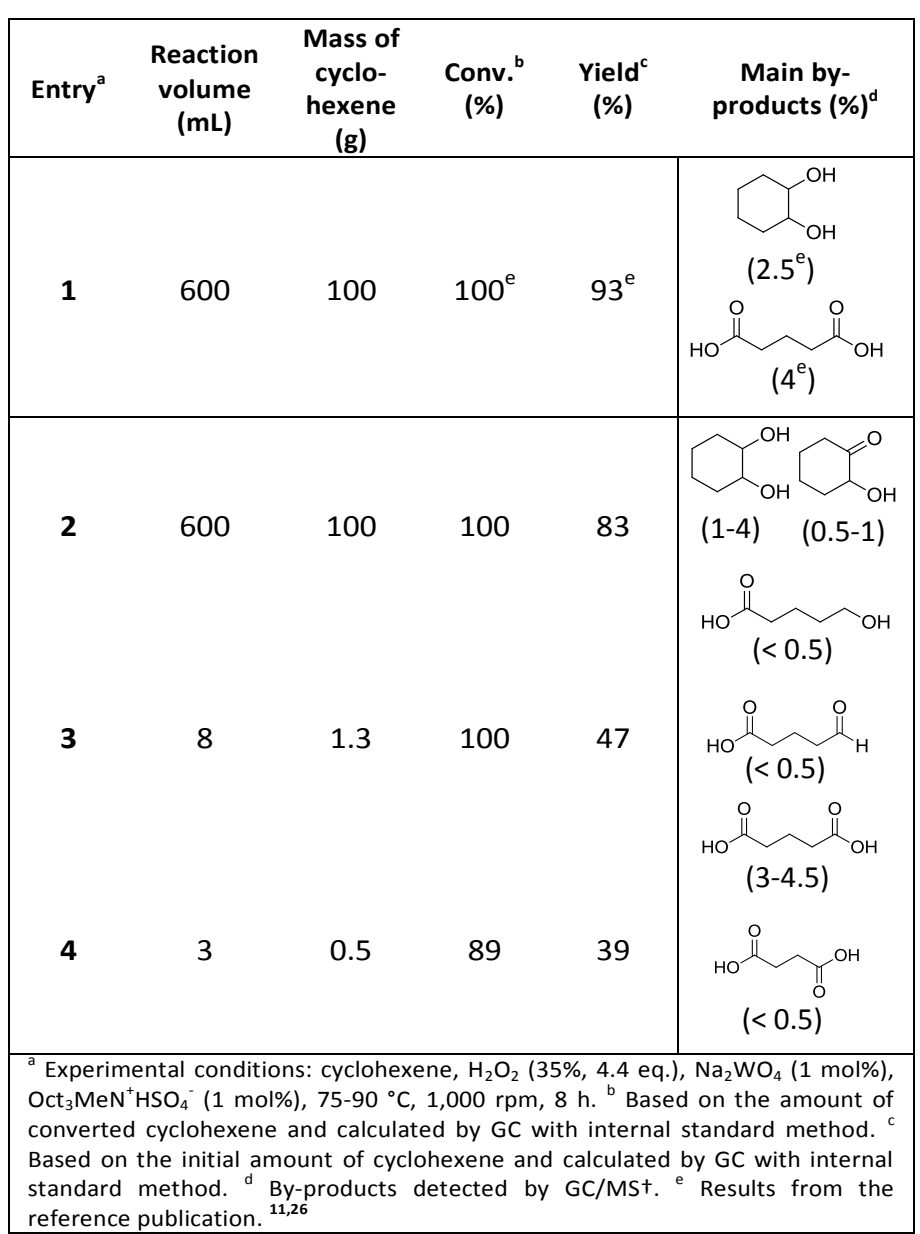

Then the oxidative cleavage of cyclohexene was studied with different associations of tungsten-based catalysts and PTC 
to compare their performance with the $\mathrm{Na}_{2} \mathrm{WO}_{4} / \mathrm{Oct}_{3} \mathrm{MeN}^{+} \mathrm{HSO}_{4}^{-}$system developed by Noyori, while following the formation of by-products. In addition, $\mathrm{H}_{2} \mathrm{WO}_{4}$ /Aliquat $336^{\circ}$ was chosen as catalytic system as it affords yields above $80 \%$ for the oxidative cleavage of cyclohexene and cyclopentene in the literature. ${ }^{30,33}$ Different combinations of $\mathrm{W}$-based catalyst and PTC were studied in order to reach a $\mathrm{pH}<3$ in the reaction medium. Indeed, a $\mathrm{pH}$ below 3 is required to ensure the formation of the active catalytic species ${ }^{26,34-36}$ and to prevent $\mathrm{H}_{2} \mathrm{O}_{2}$ from catalytic and thermal decomposition. ${ }^{18,19,37}$ Thus, the combination $\mathrm{Na}_{2} \mathrm{WO}_{4}$ /Aliquat $336^{\circ}$ was not selected as it affords a $\mathrm{pH}$ of 6 in the reaction medium. The results obtained with the different catalytic compositions are summarized in the Table 2.

Table 2 Oxidative cleavage of cyclohexene in the presence of different catalytic systems

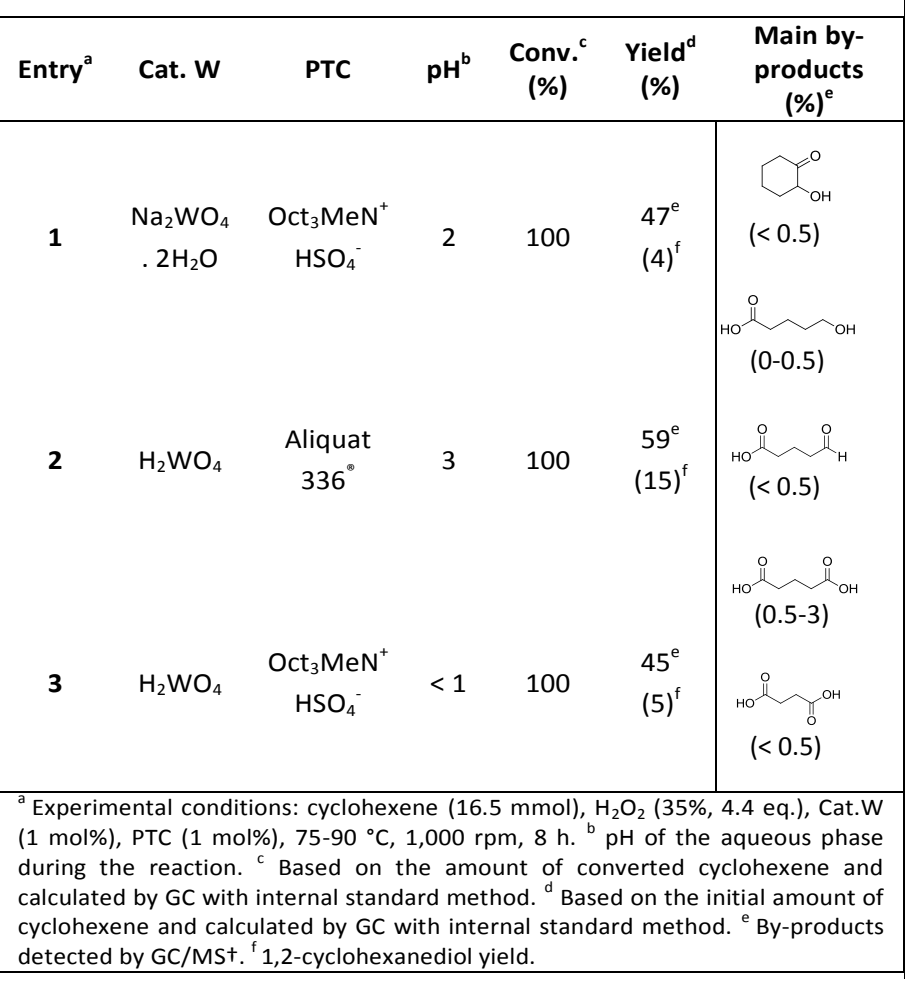

Among the catalytic systems that have been studied, the combination of tungstic acid with Aliquat $336^{\circ}$ led to the highest results with an adipic acid yield of 59\% (Table 2, Entry 2).

Under these conditions, the major intermediate is the 1,2cyclohexandiol with a yield of $15 \%$. The GC/MS analyses of the different runs revealed the formation of by-products of identical structure and in similar amount as previously (Tables 1 and 2). In order to assess a complete mechanism, the initial alkene epoxidation using $\mathrm{H}_{2} \mathrm{WO}_{4}$ and Aliquat $336^{\circ}$ has been investigated.

In a very recent study, we showed that this system combined to high frequency ultrasound particularly improved the epoxidation of cis-cyclooctene and revealed important mechanistic insights of the studied reaction. ${ }^{38}$ Hence, under $800 \mathrm{kHz}$ ultrasonic irradiation, in the presence of $0.75 \% \mathrm{~mol}$ of
$\mathrm{H}_{2} \mathrm{WO}_{4}$ and Aliquat $336^{\circ}$ and 1.5 eq. of $30 \% \mathrm{H}_{2} \mathrm{O}_{2}$ related to the substrate, $96 \%$ yield of epoxide was obtained with $98 \%$ selectivity within only $30 \mathrm{~min}$. In addition, the non-radical nature of cis-cyclooctene epoxidation mechanism has been demonstrated. ${ }^{38}$ In the present study, under magnetic stirring, the chosen oxidizing system leads to epoxycyclooctane in $89 \%$ yield and $91 \%$ selectivity (Table 3, Entry 1). The same conditions have been then used for the epoxidation of cyclohexene and cyclopentene (Table 3, Entries 2 and 3) and the structural identification of the products issued from the oxidation of these three cycloalkenes have been performed (Table 3).

Table 3 Epoxidation of cycloalkenes in the presence of $\mathrm{H}_{2} \mathrm{O}_{2}, \mathrm{H}_{2} \mathrm{WO}_{4}$ and Aliquat $336^{\circ}$

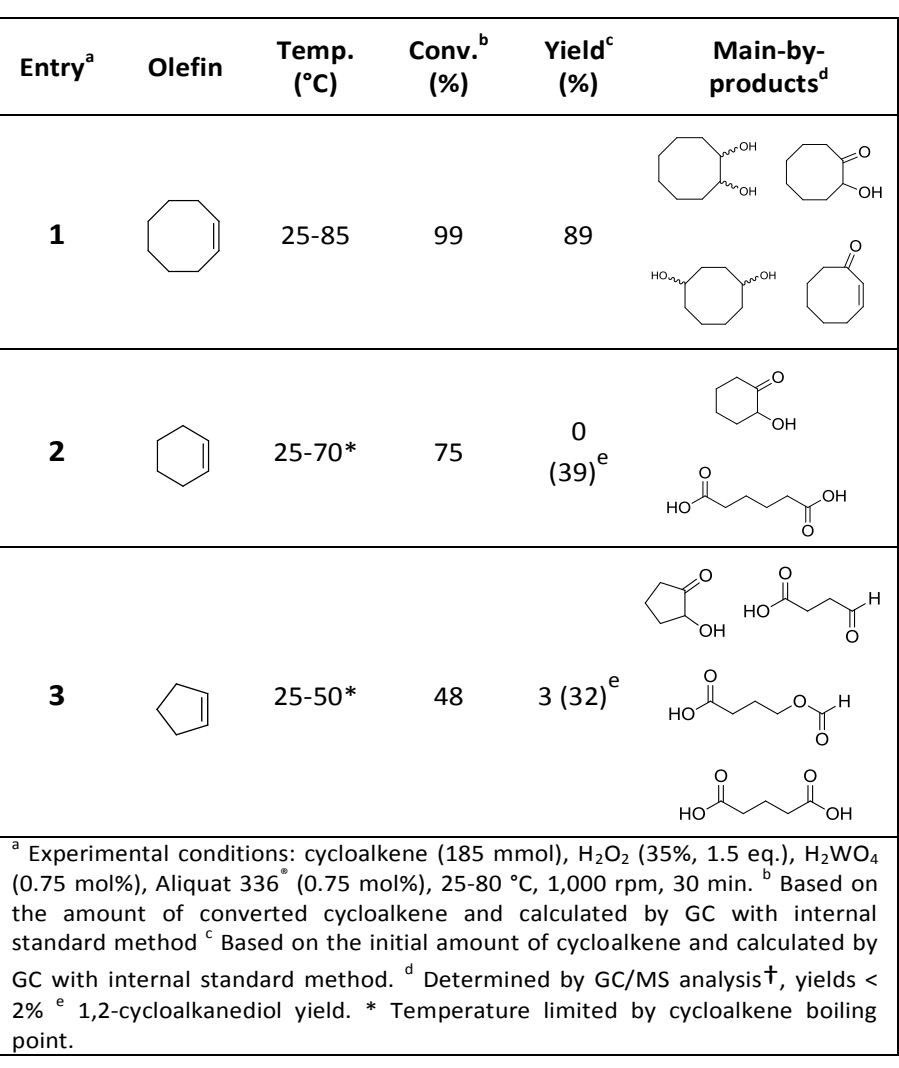

Unfortunately, in spite of the excellent epoxidation results observed with cis-cyclooctene, the oxidizing system was not efficient to selectively convert cyclohexene and cyclopentene to their corresponding epoxides in $30 \mathrm{~min}$. Indeed, while cyclooctene is almost fully transformed to epoxycyclooctane in $89 \%$ yield (Table 3, Entry 1), conversion of smaller cycloalkenes did not exceed $75 \%$ and their epoxides were observed in 0 and $3 \%$ yields (Table 3, Entries 2 and 3). These results are explained by the higher reactivity of the double bond of cyclooctene toward electrophilic oxidants compared to the one of other cycloalkenes and the strong resistance of its epoxide toward hydrolysis under acidic conditions. ${ }^{11,32,39}$ Indeed, this particular reactivity of medium-sized cycloalkenes such as cyclooctene has been attributed to transannular reactions occurring during solvolysis of their oxides, and which is related to the spatial proximity of the opposite sides of their medium-sized ring. ${ }^{32,40}$ 
The few by-products observed for cyclooctene epoxidation are its oxidative cleavage intermediates 1,2-diol and $\alpha$ hydroxyketone, a 1,4-diol formed from transannular reaction, and a product of allylic oxidation, 2-cyclooctenone (Table 3, Entry 1). With cyclohexene and cyclopentene, reaction conditions mainly led to the production of their corresponding 1,2-diols with 39 and 32\% yield respectively (Table 3, Entries 2 and 3 ). Numerous by-products arising from the oxidation of these cycloolefins were also formed with yields below $2 \%$.

Scheme 2: Mechanism for the oxidative cleavage of cyclohexene and the production of dicarboxylic acids of shorter carbon chain in the presence of $\mathrm{H}_{2} \mathrm{O}_{2}$ and a tungsten-based catalyst.

The oxidation of cyclopentene also revealed the formation of additional by-products such as 4-oxobutanoïc and 4-
Among them, oxidative cleavage products and known intermediates, previously observed in this work, such as $\alpha$ hydroxyketone and dicarboxylic acid have been detected (Table 3, Entries 2 and 3).

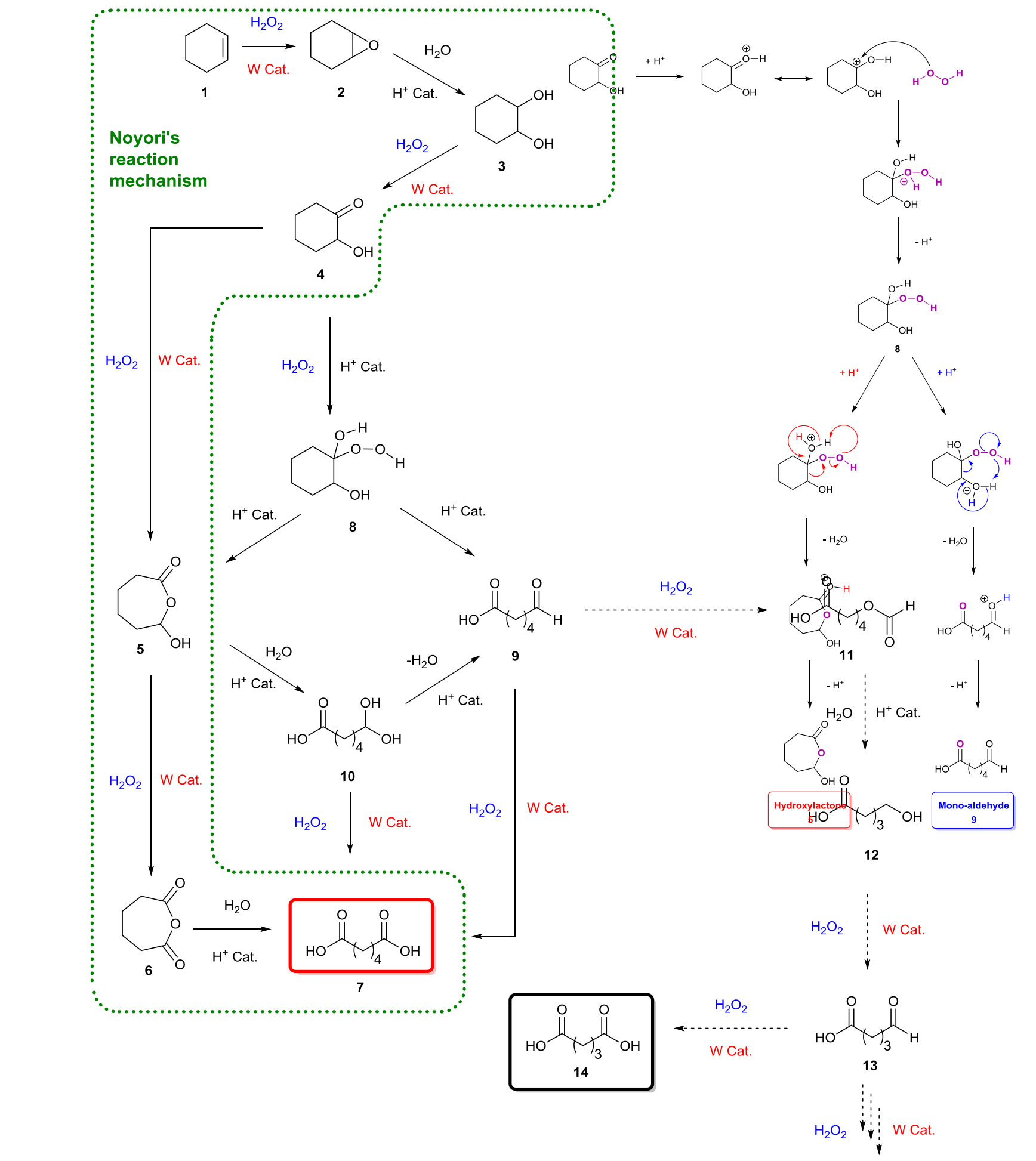


formyloxobutanoïc acids (Table 3, Entry 3). In order to understand the formation of the by-products observed during the different steps of the oxidative cleavage of cycloalkenes, their structure was determined and compared to the results described in the literature. ${ }^{11,26,30,41}$

The present study on the oxidative cleavage and epoxidation of cyclohexene and cyclopentene allows highlighting the formation of 2 categories of compounds: oxidative cleavage intermediates and by-products.

On the one hand, expected reaction intermediates such as epoxide 2, 1,2-diol 3, and hydroxy-ketone $\mathbf{4}$ have been identified (Tables 1, 2 and 3). Despite the different reaction conditions and analyses carried out within the frame of our studies, the hydroxy-lactone 5 and cyclic anhydride 6 proposed by Noyori have never been detected. (Scheme 1). ${ }^{11,26}$

Pioneering studies reported by Venturello et al. ${ }^{42}$ led us to consider other intermediates in this mechanism (Scheme. 1). In particular, the production of a hydroperoxyalcohol intermediate 8 arising from the nucleophilic addition of $\mathrm{H}_{2} \mathrm{O}_{2}$ on the hydroxy-ketone 4 has been proposed, following the identification of the mono-aldehyde 9 (Scheme 2). ${ }^{42}$ Production of a hydroperoxyalcohol from the addition of $\mathrm{H}_{2} \mathrm{O}_{2}$ on a ketone has already been justified in earlier examples. ${ }^{43,44}$ Studies of the literature on aldehyde oxidation ${ }^{45,46}$ also support the hypothesis of the formation of the carboxylic acid $\mathbf{7}$ through the oxidation of the mono-aldehyde intermediate $\mathbf{9}$. Interestingly, both mechanisms suggested by Noyori and Venturello are connected via the hydroperoxyalcohol 8 intermediate suggested by Venturello. Indeed, compound $\mathbf{8}$, also known as the Criegee intermediate, ${ }^{44,47}$ is able to rearrange to both the mono-aldehyde $\mathbf{9}$ and the hydroxylactone 5 via a Baeyer-Villiger mechanism (Schemes 2 and 3). ${ }^{29,44}$ Mechanisms proposed by Noyori and Venturello have been combined to complete the reaction scheme suggested by Noyori (Scheme 1).

In their studies on the oxidative cleavage of 1,2cyclohexanediol derivatives, Fujitani and co-workers ${ }^{41}$ proposed the production of a gem-dihydroxy acid (10 in Scheme 2) to explain the presence of the Baeyer-Villiger product 5 suggested by Noyori, and the formation of the hydroperoxyalcohol $\mathbf{8}$ and mono-aldehyde $\mathbf{9}$ suggested by Venturello. ${ }^{42}$ Nevertheless, none of these three intermediates were detected in our studies. It is worth noting that Noyori's hydroxy-lactone $\mathbf{5}$ is the result of Venturello's mono-aldehyde 9 cyclization.

Thus, regarding the numerous interconnexions existing between the above-mentioned intermediates, both pathways described in Scheme 2 should be considered to rationalize the formation of dicarboxylic acids from cycloolefin oxidative cleavage.

Scheme 3: Hypothesis of acid-catalyzed rearrangement of hydroperoxyalcohol into hydroxy-lactone 5 or mono-aldehyde 9 (adapted from references $29,31,45$ )

On the other hand, the by-products formed from sidereactions on oxidative cleavage intermediates have also been identified in this work during epoxidation and oxidative cleavage of cycloalkenes (Tables 1, 2 and 3). More specifically, dicarboxylic acids with 1 to 3 less carbon atoms compared to the targeted product have been mainly identified during epoxidation and oxidative cleavage studies. This category of by-product is often observed in the literature but no explanation has been brought to date to justify their formation. One reaction pathway that could lead to these shorter diacids could involve a decarboxylation of the desired dicarboxylic acid. ${ }^{4}$ Nevertheless, thermal decarboxylation of dicarboxylic acids mainly occurs at temperatures above $290^{\circ} \mathrm{C}^{6}$ and usually leads to the corresponding alkanes. Besides, it was shown in the literature that $\alpha$-oxoacids can afford diacids shortened by one carbon by decarboxylation in the presence of $\mathrm{H}_{2} \mathrm{O}_{2}{ }^{48}$

The production of shorter dicarboxylic acids could be explained by a $\mathrm{H}_{2} \mathrm{O}_{2}$-mediated Baeyer-Villiger oxidation of the mono-aldehyde intermediate $\mathbf{9}$. Indeed, while the reaction between an aldehyde and hydrogen peroxide generally leads to the formation of the corresponding carboxylic acid, the nucleophilic addition of $\mathrm{H}_{2} \mathrm{O}_{2}$ on the aldehyde gives rise to a high-energy hydroperoxyalcohol intermediate that rearranges into formate ester (Scheme 4)..$^{18,43,44,47}$ The formation of the carboxylic acid and the formate ester from the rearrangement of the Criegee intermediate can take place via the nucleophilic addition of either $\mathrm{H}_{2} \mathrm{O}_{2}$ or peroxotungstate complexes to the mono-aldehyde. ${ }^{45}$ Once formed, the formate ester (Scheme 2, 11) is next hydrolysed to the alcohol $\mathbf{1 2}$ (Scheme 2) that is directly oxidized to the corresponding mono-aldehyde and dicarboxylic acid (Scheme 2, 13 and 14). The consecutive Baeyer-Villiger oxidations, ester hydrolyses and alcohol oxidations from the oxo-carboxylic acid intermediate 13 (Scheme 2) also lead to dicarboxylic acids with shorter chains (Scheme 2, 15). In this study on cycloalkenes oxidation, the formate ester $\mathbf{1 1}$ has been detected (Table 3, Entry 3) as well as the hydroxy-acid $\mathbf{1 2}$ and oxo-acid 13 (Table 1, 2 and 3). In the literature, the formation of intermediates such as $\mathbf{1 2}, \mathbf{1 3}$ and $\mathbf{1 5}$ has been detected during alcohols and aldehydes oxidation using $\mathrm{H}_{2} \mathrm{O}_{2}$ and phosphotungstic acid. ${ }^{45}$ In addition to the expected carboxylic acids obtained by oxidation of linear and aromatic aldehydes, the presence of formate esters and their alcohol derivatives has been detected, thus supporting the hypothesis of the implementation of a Baeyer-Villiger oxidation. ${ }^{45}$ In addition, Venturello and co-workers also described the presence of this side reaction during the oxidative cleavage of 1-methylcyclohexene. Indeed, 5acetoxypentanoic acid was shown to be formed as a byproduct along with the targeted 6-oxoheptanoïc acid. ${ }^{30}$

Thus, the mechanism disclosed in the Scheme 2 for the production of shorter chain diacids confirms the formation of the mono-aldehyde intermediate $\mathbf{9}$ as a key intermediate in the oxidative cleavage mechanism of cycloalkenes. Finally, this mechanism also explains the formation of shorter chain diacids observed during linear alkene oxidative cleavage, for which formation of aldehyde intermediates is well-established in the literature. ${ }^{3,4,49}$ 


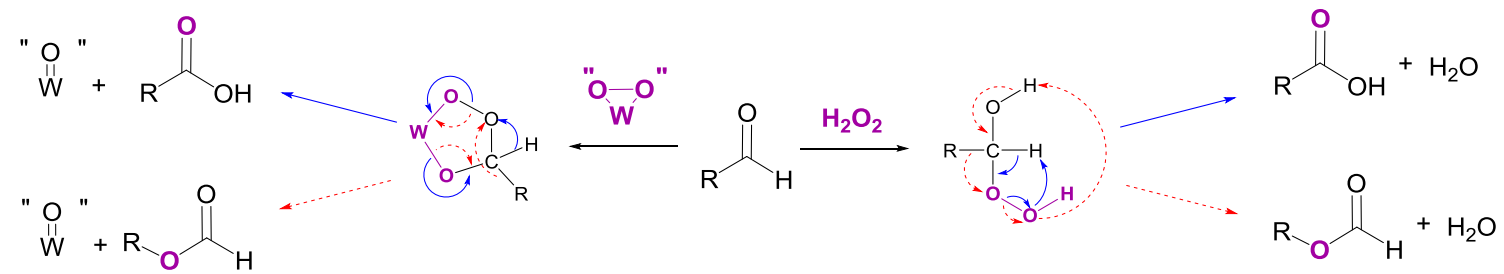

Scheme 4: Competitive oxidation pathways occurring during aldehyde oxidation in the presence of $\mathrm{H}_{2} \mathrm{O}_{2}$ and a tungsten-based catalyst. In blue: aldehyde oxidation into carboxylic acid. In red dotted lines: Baeyer-Villiger oxidation (adapted from references 18,45).

\section{Conclusions}

To summarize, this work proposes a complete mechanism of formation of the products and by-products obtained during the oxidative cleavage of cycloalkenes with $\mathrm{H}_{2} \mathrm{O}_{2}$ and $\mathrm{H}_{2} \mathrm{WO}_{4}$. The reaction has been studied with cyclohexene and cyclopentene under various conditions. The structures and proportions of identified by-products were studied from epoxidation/dihydroxylation and oxidative cleavage stages. The present study shows that, along with targeted compounds, dicarboxylic acids shortened by 1 to 3 carbon atoms compared to the expected ones are mainly formed. The production of these by-products is explained by a BaeyerVilliger oxidation on a mono-aldehyde intermediate that leads to a formate ester, which is hydrolysed and then oxidized to shorter chain diacids. This hypothesis is supported by the identification of formate esters and hydroxyacids but also by results on $\mathrm{H}_{2} \mathrm{O}_{2}$-mediated alcohol and aldehyde oxidation published in the literature, illustrating the formation of a mono-aldehyde intermediate in the cycloalkene oxidative cleavage pathway. The mechanism proposed in this study constitutes a real support for researchers aiming at developing efficient and environmentally-friendly methodologies for the oxidative cleavage of olefins with $\mathrm{H}_{2} \mathrm{O}_{2}$ and tungsten-based catalysts.

\section{Conflicts of interest}

There are no conflicts to declare.

\section{Acknowledgements}

The authors are grateful to the Région Auvergne Rhône-Alpes for the financial support through an ARC Environnement doctoral research grant (ARC 2016).

\section{Notes and references}

1 M. Rüsch, Gen. Klaas, P. Bavaj and S. Warwel, Fett Wissenschaft Technologie/Fat Science Technology, 1995, 97, 359-367.

2 P. Spannring, P. C. A. Bruijnincx, Bert. M. Weckhuysen and R. J. M. Klein Gebbink, Catal. Sci. Technol., 2014, 4, 2182.

3 A. Enferadi Kerenkan, F. Béland and T.-O. Do, Catal. Sci. Technol., 2016, 6, 971-987.
4 A. Soutelo-Maria, J.-L. Dubois, J.-L. Couturier and G. Cravotto, Catalysts, 2018, 8, 464.

5 T. Cousin, G. Chatel, N. Kardos, B. Andrioletti and M. Draye, Catal. Sci. Technol., 2019, 9, 5256-5278.

6 B. Cornils and P. Lappe, in Ullmann's Encyclopedia of Industrial Chemistry, ed. Wiley-VCH Verlag GmbH \& Co. KGaA, Wiley-VCH Verlag GmbH \& Co. KGaA, Weinheim, Germany, 2000.

7 M. T. Musser, in Ullmann's Encyclopedia of Industrial Chemistry, ed. Wiley-VCH Verlag GmbH \& Co. KGaA, Wiley-VCH Verlag GmbH \& Co. KGaA, Weinheim, Germany, 2000.

8 C. H. Hamblet and M. Amborse, US Pat., 2557282A, 1951.

9 J. H. Teles, I. Hermans, G. Franz and R. A. Sheldon, in Ullmann's Encyclopedia of Industrial Chemistry, ed. Wiley-VCH Verlag $\mathrm{GmbH} \&$ Co. KGaA, Wiley-VCH Verlag GmbH \& Co. KGaA, Weinheim, Germany, 2015, 1-103.

10 J. C. J. Bart and S. Cavallaro, Industrial \& Engineering Chemistry Research, 2015, 54, 1-46.

11 K. Sato, M. Aoki and R. Noyori, Science, 1998, 281, 1646-1647.

12 C. Bolm, O. Beckmann and O. A. G. Dabard, Angewandte Chemie International Edition, 1999, 38, 907-909.

13 R. E. Dickinson and R. J. Cicerone, Nature, 1986, 319, 109-115.

14 R. A. Reimer, C. S. Slaten, M. Seapan, M. W. Lower and P. E. Tomlinson, Environmental Progress, 1994, 13, 134-137.

15 R. A. Reimer, C. S. Slaten, M. Seapan, T. A. Koch and V. G. Triner, in Non- $\mathrm{CO}_{2}$ Greenhouse Gases: Scientific Understanding, Control and Implementation, eds. J. van Ham, A. P. M. Baede, L. A. Meyer and R. Ybema, Springer Netherlands, Dordrecht, 2000, 347-358.

16 F. Cavani and S. Alini, in Sustainable Industrial Chemistry, eds. F. Cavani, G. Centi, S. Perathoner and F. Trifir, Wiley-VCH Verlag GmbH \& Co. KGaA, Weinheim, Germany, 2009, 367-425.

17 A. Shimizu, K. Tanaka and M. Fujimori, Chemosphere - Global Change Science, 2000, 2, 425-434.

18 C. W. Jones, Applications of hydrogen peroxide and derivatives, Royal Society of Chemistry, Cambridge, 1999.

19 R. Ciriminna, L. Albanese, F. Meneguzzo and M. Pagliaro, ChemSusChem, 2016, 9, 3374-3381.

20 C. P. Horwitz, in Innovations in Green Chemistry and Green Engineering, eds. P. T. Anastas and J. B. Zimmerman, Springer New York, New York, NY, 2013, 247-295.

21 E. Lassner, W.-D. Schubert, E. Lüderitz and H. U. Wolf, in Ullmann's Encyclopedia of Industrial Chemistry, ed. Wiley-VCH Verlag GmbH \& Co. KGaA, Wiley-VCH Verlag GmbH \& Co. KGaA, Weinheim, Germany, 2000.

22 National Research Council (U.S.)., Handbook of toxicology., Saunders, Philadelphia, 1956.

23 P. E. Leffler and G. Kazantzis, in Handbook on the Toxicology of Metals, Elsevier, 2015, 1297-1306.

24 W. P. Griffith, Transition Metal Chemistry, 1991, 16, 548-552. 
25 L. Salles, C. Aubry, R. Thouvenot, F. Robert, C. Doremieux-Morin, G. Chottard, H. Ledon, Y. Jeannin and J. M. Bregeault, Inorganic Chemistry, 1994, 33, 871-878.

26 R. Noyori, M. Aoki and K. Sato, Chemical Communications, 2003, 1977.

27 L. Knof, Justus Liebigs Annalen der Chemie, 1962, 656, 183-189.

28 G. M. Rubottom, J. M. Gruber, R. K. Boeckman, M. Ramaiah and J. B. Medwid, Tetrahedron Letters, 1978, 19, 4603-4606.

29 P. Jin, L. Zhu, D. Wei, M. Tang and X. Wang, Computational and Theoretical Chemistry, 2011, 966, 207-212.

30 E. Antonelli, R. D'Aloisio, M. Gambaro, T. Fiorani and C. Venturello, The Journal of Organic Chemistry, 1998, 63, 71907206.

31 K. Fujitani, T. Mizutani, T. Oida and T. Kawase, Journal of Oleo Science, 2009, 58, 37-42.

32 A. C. Cope, M. M. Martin and M. A. McKervey, Quarterly Reviews, Chemical Society, 1966, 20, 119.

33 P. U. Maheswari, P. De Hoog, P. G. Enamorado, R. Hage and J. Reedijk, WO2009109857, 2009.

34 N. J. Campbell, A. C. Dengel, C. J. Edwards and W. P. Griffith, Journal of the Chemical Society, Dalton Transactions, 1989, 1203.

35 A. J. Bailey, W. P. Griffith and B. C. Parkin, Journal of the Chemical Society, Dalton Transactions, 1995, 1833.

36 A. C. Dengel, W. P. Griffith and B. C. Parkin, J. Chem. Soc., Dalton Trans., 1993, 2683-2688.

37 G. Strukul, Catalytic Oxidations with Hydrogen Peroxide as Oxidant, Springer Netherlands, 1992.

38 T. Cousin, G. Chatel, N. Kardos, B. Andrioletti and M. Draye, Ultrasonics Sonochemistry, 2019, 53, 120-125.

39 S. A. Hauser, M. Cokoja and F. E. Kühn, Catal. Sci. Technol., 2013, 3, 552-561.

40 A. C. Cope, A. Fournier and H. E. Simmons, Journal of the American Chemical Society, 1957, 79, 3905-3909.

$41 \mathrm{~K}$. Fujitani, T. Mizutani, T. Oida and T. Kawase, Journal of Oleo Science, 2009, 58, 323-328.

42 C. Venturello and M. Ricci, The Journal of Organic Chemistry, 1986, 51, 1599-1602.

43 A. Rieche, Angew. Chem., 1958, 70, 251-266.

44 C. H. Hassall, in Organic Reactions, ed. John Wiley \& Sons, Inc., John Wiley \& Sons, Inc., Hoboken, NJ, USA, 1957, 73-106.

45 C. Venturello and M. Gambaro, The Journal of Organic Chemistry, 1991, 56, 5924-5931.

46 K. Sato, M. Aoki, J. Takagi and R. Noyori, Journal of the American Chemical Society, 1997, 119, 12386-12387.

47 G. R. Krow, in Organic Reactions, ed. John Wiley \& Sons, Inc., John Wiley \& Sons, Inc., Hoboken, NJ, USA, 1993, 251-798.

48 A. Lopalco, G. Dalwadi, S. Niu, R. L. Schowen, J. Douglas and V. J. Stella, Journal of Pharmaceutical Sciences, 2016, 105, 705-713.

49 A. Godard, P. de Caro, E. Vedrenne, Z. Mouloungui and S. Thiebaud-Roux, OCL, 2016, 23, D510. 